\title{
An Analysis of Malocclusion and Occlusal Characteristics in Nepolese Orthodontic Patients
}

\author{
Dr Sujita Shrestha,' Dr Rabindra Man Shrestha² \\ 'Lecturer, Dept of Community \& Public Health Dentistry, ${ }^{2}$ Associate Professor, Dept of Orthodontics \\ Kantipur Dental College, Kathmandu, Nepal \\ Correspondence: shresthasujita@hotmail.com
}

\section{ABSTRACT}

Objective: To analyze the prevalence of malocclusion and occlusal characteristics in referred Nepalese orthodontic patients with respect to age, gender, Angle's classification.

Materials \& Method: Study models of 464 orthodontic patients ( 165 male and 299 female) of the age ranging from 11 to 30 years were studied to evaluate the prevalence of malocclusion using Angle's classification and occlusal characteristics of overjet, overbite, open bite, cross bite, displacement, and hypodontia according to the method of Dental Health Component of Index of Orthodontic Treatment Need. The association between DHC grades and Angle's classification and gender were assessed using chi-square test $(p<0.01)$.

Result: The malocclusion status among the Nepalese seeking orthodontic treatment was $54.7 \%$ Class I, $36.9 \%$ Class II, and $8.4 \%$ Class III. The occurrence of occlusal discrepancies were overjet in $43.8 \%$, increased overbite in $20.7 \%$, open bite in $8.2 \%$, cross bite in $23.3 \%$, displacement in $65.7 \%$ and hypodontia in $11.3 \%$.

Conclusion: $16.2 \%$ required no/little treatment need, $20.4 \%$ required borderline treatment need, and $63.4 \%$ required great/severe treatment need according to DHC scale. There was statistically significant association between DHC grades and distribution of malocclusion and gender of the Nepalese subjects.

Key words: Angle's classification, dental health component, malocclusion, orthodontic patients

\section{INTRODUCTION}

Facial esthetics and perfect smile are important determinants for individual's self-esteem and social acceptance. World Health Organization defines health as "a state of complete physical, mental and social well-being and not merely the absence of disease or infirmity". Consequently, a person cannot be considered completely healthy if malocclusion prevents him/her from attaining this state of complete well-being, whether for physical (functional impairment) or psycho-social (serious impairment of self-esteem or dentofacial esthetics) reasons. In fact malocclusion is not an illness but an occlusal condition that lies within the boundaries of all possible occlusal discrepancies.

In recent years, much attention has been focused on assessment and measurement of severity and prevalence of malocclusion. Several epidemiological studies use indices or clinical assessment methods to assess prevalence and occlusal characteristics of malocclusions among the population with respect to age, gender, ethnic groups etc. Some authors measured single/multiple occlusal traits ${ }^{1,2,3}$ and others studied malocclusion using Angle's classification system. ${ }^{4}$ Consequently, orthodontic indices such as Dental Aesthetic Index, ${ }^{5}$ Treatment Priority Index, ${ }^{6}$ Index of Complexity Outcome and Need, ${ }^{7}$ and Index of Orthodontic Treatment Need (IOTN)8 were introduced.

IOTN was first developed in Britain as a system for grading malocclusion. The IOTN is based on Dental Health Component (DHC) and Aesthetic Component (AC). ${ }^{8,9}$ Lunn et a ${ }^{10}$ made IOTN easier to use by reducing the DHC grades from five to three scales. Burden et $\mathrm{a}^{11}$ further proposed a modification specifically 
for epidemiological studies to reduce the number of grades to two. They used the acronym MOCDO (Missing teeth, Overjet, Cross bite, Displacement of contact points, Over bite) to speed up the process and to select the patients that need treatment.

The objective of the present study was to analyze the prevalence of malocclusion and occlusal characteristics such as overjet, overbite, open bite, cross bite, displacement, and hypodontia in referred Nepalese orthodontic patients with respect to age, gender and Angle's classification.

\section{MATERIALS AND METHOD}

A total of 464 patients with 165 male and 299 female of the age ranging from 11 to 30 years were included in the study. The study was conducted among the patients of Department of Orthodontics, Kantipur Dental College Teaching Hospital \& Research Center (KDCH), Kathmandu who were seeking orthodontic treatment during May 2008 to May 2013. The subjects were evaluated using dental stone study models from the patient record. The study models were examined and graded by a specialist orthodontist; the co-author of the present study.

The study analyzed the prevalence of malocclusion using Angle's classification and occlusal characteristics like overjet, overbite, open bite, cross bite, displacement, and hypodontia among the patients. These occlusal triats are measurable clinical characteristics which help to assess malocclusion and are used by Dental Health Component of IOTN. All statistical analyses were performed by using SPSS 16.0 version. Descriptive statistics were calculated for the prevalence of malocclusion, occlusal characteristics and DHC grades. The association between DHC grades and Angle's classification of malocclusion, and gender were assessed using chi-square test ( $p<0.01)$.

\section{Variables used in the study:}

Molar relationship: The relationship between upper and lower first permanent molars were used to determine Angle's Class I, Class II or Class III malocclusions.

Overjet: Values between 0 to $3 \mathrm{~mm}$ were considered normal. Increased overjet greater than $3.5 \mathrm{~mm}$ but less than or equal to $6 \mathrm{~mm}$ with competent lips was coded as ' $2 a$ '. Increased overjet greater than $3.5 \mathrm{~mm}$ but less than or equal to $6 \mathrm{~mm}$ with incompetent lips was coded as ' $3 a$ '. Increased overjet greater than 6 $\mathrm{mm}$ but less than or equal to $9 \mathrm{~mm}$ was coded as ' $4 \mathrm{a}$ ' and increased overjet greater than $9 \mathrm{~mm}$ was coded as ' $5 a$ '. The categories ' $2 a$ ' and ' $3 a$ ' were combined as the lip competency could not be evaluated from the study model.

Overbite: Values between 0 to $3 \mathrm{~mm}$ were considered normal. Increased overbite greater than or equal to $3.5 \mathrm{~mm}$ without gingival contact were coded as ' $2 \mathrm{f}$ '. Complete overbite without gingival or palatal trauma was coded as ' $3 f$ ' and increased or complete overbite with gingival or palatal trauma was coded as ' $4 \mathrm{f}$ '.

Anterior/Posterior cross bite: Anterior or posterior cross bite was diagnosed when there was a crossover of at least one tooth in the anterior or posterior region of the dental arch. Cross bite with less than or equal to 1 $\mathrm{mm}$ discrepancy between retruded contact position and intercuspal position was coded as '2c'. Cross bite with greater than $1 \mathrm{~mm}$ but less than or equal to $2 \mathrm{~mm}$ discrepancy was coded as ' $3 c$ '. Cross bite with greater than $2 \mathrm{~mm}$ discrepancy was coded as ' $4 \mathrm{c}$ '.

Displacement: Displacement is the distance between the natural contact points of the adjacent teeth; which is not a measure of crowding. Displacement of teeth greater than $1 \mathrm{~mm}$ but less than or equal to 2 $\mathrm{mm}$ was coded as '2d'. Displacement greater than $2 \mathrm{~mm}$ but less than or equal to $4 \mathrm{~mm}$ was coded as ' $3 d$ '. Severe displacements of teeth greater than $4 \mathrm{~mm}$ were coded as '4d'.

Open bite: Anterior or posterior/lateral open bite greater than $1 \mathrm{~mm}$ but less than or equal to $2 \mathrm{~mm}$ was coded as ' $2 e$ '. Open bite greater than $2 \mathrm{~mm}$ but less than or equal to $4 \mathrm{~mm}$ was coded as ' $3 e$ '. Extreme anterior or lateral open bite greater than $4 \mathrm{~mm}$ was coded as ' $4 e$ '.

Hypodontia (Missing): Less extensive hypodontia requiring pre-restorative orthodontics or orthodontic space closure to obviate the need for prosthesis was coded as ' $4 h$ '. Extensive hypodontia with restorative implications of more than one tooth missing in any quadrant requiring pre-restorative orthodontics was coded as '5h'. 


\section{RESULT}

In the present study, dental stone models of 464 subjects seeking orthodontic treatment including 165 (35.6\%) male and 299 (64.4\%) female were analyzed. The age of the subjects ranged from 11 to 30 years with mean age 17.32 years. Among 464 patients, 196 (42.2\%) were of age group 11-15 years, 172 (37.1\%) were 16-20 years, 65 (14\%) were $21-25$ years and 31 (6.7\%) were $26-30$ years of age.

According to Angle's classification; the patients' malocclusion status were 254 (54.7\%) Class I, 171 (36.9\%) Class II, and 39 (8.4\%) Class III (Figure 1). Table 1 and Table 2 represent frequency distribution of Angle's classification according to gender and age groups respectively.

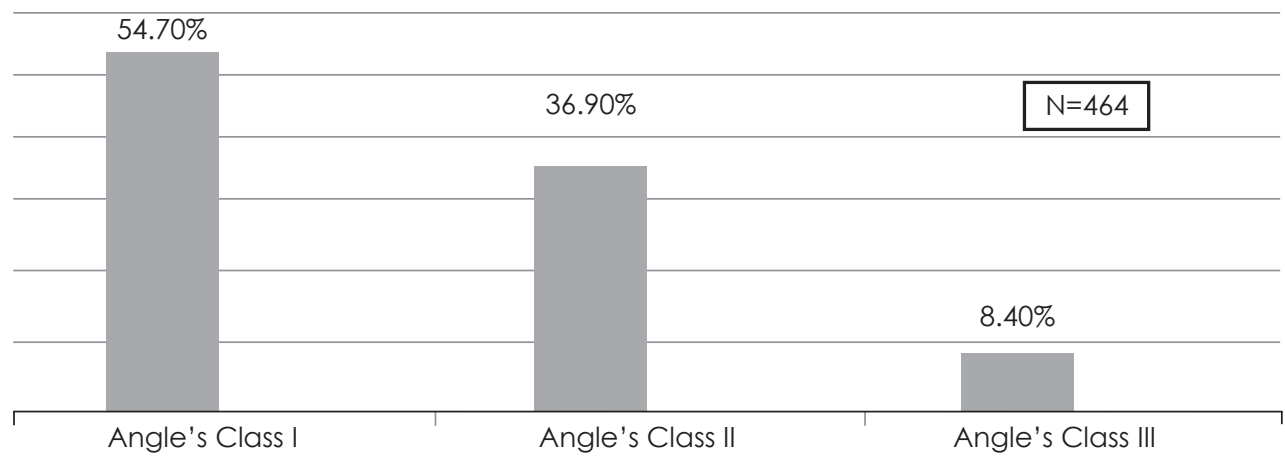

Figure1: Distribution of subjects according to Angle's classification of malocclusion

Table 1: Distribution of malocclusion according to gender

\begin{tabular}{|l|c|c|c|}
\hline \multirow{2}{*}{ Angle's classification } & \multicolumn{2}{|c|}{ Gender } & Total \\
\cline { 2 - 4 } & Male & $174(68.50 \%)$ & $254(54.70 \%)$ \\
\hline Class I & $80(31.50 \%)$ & $102(59.65 \%)$ & $171(36.90 \%)$ \\
\hline Class II & $69(40.35 \%)$ & $23(58.97 \%)$ & $39(8.40 \%)$ \\
\hline Class III & $16(41.03 \%)$ & $299(64.40 \%)$ & $464(100 \%)$ \\
\hline
\end{tabular}

Table 2: Distribution of malocclusion according to age group

\begin{tabular}{|c|c|c|c|c|c|}
\hline \multirow{2}{*}{ Angle's classification } & \multicolumn{4}{|c|}{ Age Group } & \multirow{2}{*}{ Total } \\
\hline & $11-15$ years & $16-20$ years & 21-25 years & $26-30$ years & \\
\hline Class I & 100 (39.37\%) & 95 (37.40 \%) & 41 (16.14\%) & 18 (7.09\%) & 254 \\
\hline Class II & $75(43.86 \%)$ & $70(40.94 \%)$ & $18(10.52 \%)$ & $8(4.68 \%)$ & 171 \\
\hline Class III & 21 (53.85 \%) & 7 (17.95 \%) & 6 (15.38 \%) & 5 (12.82 \%) & 39 \\
\hline Total & $196(42.2 \%)$ & 172 (37.1 \%) & 65 (14.0\%) & 31 (6.7 \%) & 464 \\
\hline
\end{tabular}

The present study showed increased overjet in $43.8 \%$ subjects with $6.9 \%$ showing overjet more than $9 \mathrm{~mm}$. Similarly, increased overbite was seen $20.7 \%$ with $19.2 \%$ subjects showing complete overbite. Varying levels of open bite was found in $8.2 \%$ subjects and cross bite was found in $23.3 \%$. Displacement was found in $65.7 \%$ with $37.1 \%$ showing displacement more than $4 \mathrm{~mm}$. Hypodontia was seen in $11.3 \%$ with $2.2 \%$ requiring pre-restorative orthodontic treatment for more than one tooth missing among the Nepalese seeking orthodontic treatment (Table 3). 
Table 3: Frequency distribution of Angle's classification according to occlusal characteristics

\begin{tabular}{|c|c|c|c|c|c|c|}
\hline \multicolumn{2}{|r|}{ Malocclusion } & $\begin{array}{c}\text { DHC } \\
\text { notation }\end{array}$ & $\begin{array}{c}\text { Class I } \\
(\mathrm{N}=254)\end{array}$ & $\begin{array}{c}\text { Class II } \\
(\mathrm{N}=171)\end{array}$ & $\begin{array}{l}\text { Class III } \\
(\mathrm{N}=39)\end{array}$ & $\begin{array}{c}\text { Total } \\
(\mathrm{N}=464)\end{array}$ \\
\hline \multirow{4}{*}{ Overjet } & Normal & - & $175(68.9 \%)$ & $47(27.495 \%)$ & $39(100 \%)$ & $261(56.2 \%)$ \\
\hline & $\geq 3.5 \mathrm{~mm}$ (without gingival contact) & $2 f$ & $6(2.36 \%)$ & $1(0.58 \%)$ & 0 & $7(1.5 \%)$ \\
\hline & Complete (w/o gingival trauma) & $3 f$ & $13(5.12 \%)$ & $13(7.60 \%)$ & 0 & $26(5.6 \%)$ \\
\hline & Complete (w/ gingival trauma) & $4 f$ & $19(7.48 \%)$ & $43(25.15 \%)$ & $1(2.56 \%)$ & $63(13.6 \%)$ \\
\hline \multirow{4}{*}{$\begin{array}{l}\text { Over- } \\
\text { bite }\end{array}$} & Normal & - & $231(90.94 \%)$ & $166(97.08 \%)$ & $29(74.36 \%)$ & $426(91.8 \%)$ \\
\hline & $>1 \mathrm{~mm}$ to $\leq 2 \mathrm{~mm}$ & $2 e$ & $3(1.18 \%)$ & 0 & 0 & $3(0.6 \%)$ \\
\hline & $>2 \mathrm{~mm}$ to $\leq 4 \mathrm{~mm}$ & $3 e$ & $7(2.76 \%)$ & 0 & $3(7.69 \%)$ & $10(2.2 \%)$ \\
\hline & $>4 \mathrm{~mm}$ & $4 e$ & $13(5.12 \%)$ & $5(2.92 \%)$ & 7 (17.95\%) & $25(5.4 \%)$ \\
\hline \multirow{4}{*}{$\begin{array}{l}\text { Open } \\
\text { bite } \\
\text { (Antr/ } \\
\text { Postr) }\end{array}$} & Normal & - & $188(74.02 \%)$ & 153 (89.47 \%) & $15(38.46 \%)$ & $356(76.7 \%)$ \\
\hline & $\leq 1 \mathrm{~mm}$ & $2 c$ & $6(2.36 \%)$ & 0 & $1(2.56 \%)$ & $7(1.5 \%)$ \\
\hline & $1 \mathrm{~mm}$ to $\leq 2 \mathrm{~mm}$ & $3 c$ & $19(7.48 \%)$ & $4(2.34 \%)$ & $9(23.08 \%)$ & $32(6.9 \%)$ \\
\hline & $>2 \mathrm{~mm}$ & $4 c$ & $41(16.14 \%)$ & $14(8.14 \%)$ & 14 (35.90\%) & $69(14.9 \%)$ \\
\hline \multirow{4}{*}{$\begin{array}{l}\text { Cross } \\
\text { bite } \\
\text { (Antr/ } \\
\text { Postr) }\end{array}$} & Normal & - & $188(74.02 \%)$ & 153 (89.47\%) & $15(38.46 \%)$ & $356(76.7 \%)$ \\
\hline & $\leq 1 \mathrm{~mm}$ & $2 c$ & $6(2.36 \%)$ & 0 & $1(2.56 \%)$ & $7(1.5 \%)$ \\
\hline & $1 \mathrm{~mm}$ to $\leq 2 \mathrm{~mm}$ & $3 c$ & $19(7.48 \%)$ & $4(2.34 \%)$ & 9 (23.08 \%) & $32(6.9 \%)$ \\
\hline & $>2 \mathrm{~mm}$ & $4 c$ & $41(16.14 \%)$ & $14(8.14 \%)$ & $14(35.90 \%)$ & $69(14.9 \%)$ \\
\hline \multirow{4}{*}{$\begin{array}{l}\text { Dis- } \\
\text { plac- } \\
\text { ement }\end{array}$} & Normal & - & 88 (34.65 \%) & 53 (30.99 \%) & $18(46.15 \%)$ & $159(34.3 \%)$ \\
\hline & $>1 \mathrm{~mm}$ to $\leq 2 \mathrm{~mm}$ & $2 d$ & $47(18.50 \%)$ & $6(3.51 \%)$ & 0 & $53(11.4 \%)$ \\
\hline & $>2 \mathrm{~mm}$ to $\leq 4 \mathrm{~mm}$ & $3 d$ & $42(16.54 \%)$ & $30(17.54 \%)$ & $8(20.52 \%)$ & $80(17.2 \%)$ \\
\hline & $>4 \mathrm{~mm}$ & $4 d$ & 77 (30.31 \%) & 82 (47.95 \%) & $13(33.33 \%)$ & $172(37.1 \%)$ \\
\hline \multirow{3}{*}{$\begin{array}{l}\text { Hypo- } \\
\text { dontia }\end{array}$} & Normal & - & $222(87.40 \%)$ & $153(89.47 \%)$ & $37(94.88 \%)$ & 412 (88.8 \%) \\
\hline & Less extensive & $4 \mathrm{~h}$ & 27 (10.63 \%) & $14(8.19 \%)$ & $1(2.56 \%)$ & 42 (9.1\%) \\
\hline & Extensive & $5 \mathrm{~h}$ & 5 (1.97\%) & $4(2.34 \%)$ & $1(2.56 \%)$ & $10(2.2 \%)$ \\
\hline
\end{tabular}

Among 464 patients examined; the distribution of DHC scale was 75 (16.2\%) for no/little treatment need, 95 (20.4\%) for borderline treatment need, and 294 (63.4\%) for great/severe treatment need (Figure 2).

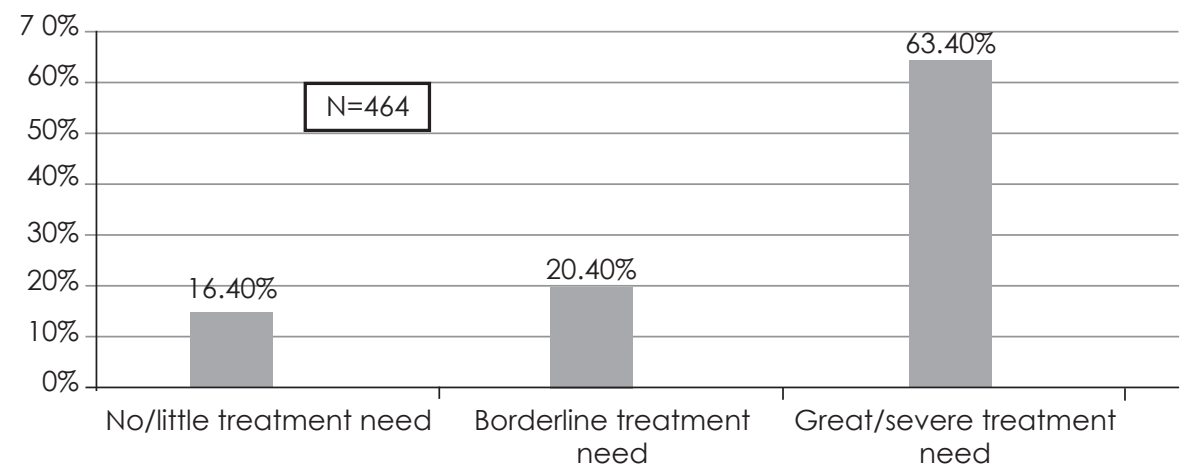

Figure 2: Distribution of Dental Health Component

The study depicted statistically significant association between DHC grades and distribution of malocclusion according to Angle's classification and gender groups among Nepalese orthodontic patients $(p<0.01)($ Table 4,5$)$. 
Table 4: Frequency distribution and test of association between DHC grade and Gender

\begin{tabular}{|c|c|c|c|c|c|}
\hline \multirow[b]{2}{*}{ Gender } & \multicolumn{3}{|c|}{ DHC grade } & \multirow[b]{2}{*}{ Total } & \multirow[b]{2}{*}{$p$-value } \\
\hline & $\begin{array}{l}\text { No/little } \\
\text { treatment need }\end{array}$ & $\begin{array}{l}\text { Borderline } \\
\text { treatment need }\end{array}$ & $\begin{array}{l}\text { Great/severe } \\
\text { treatment need }\end{array}$ & & \\
\hline Male & 15 (9.09\%) & 31 (18.79\%) & 119 (72.12\%) & 165 & \multirow{3}{*}{$0.003^{*}$} \\
\hline Female & $60(20.41 \%)$ & $64(21.77 \%)$ & 175 (59.52\%) & 294 & \\
\hline Total & $75(16.2 \%)$ & $95(20.4 \%)$ & 294 (63.4\%) & 464 & \\
\hline
\end{tabular}

Table 5: Frequency distribution and test of association between DHC grade and malocclusion

\begin{tabular}{|l|c|c|c|c|c|}
\hline \multirow{2}{*}{$\begin{array}{l}\text { Angle's classification } \\
\text { of malocclusion }\end{array}$} & $\begin{array}{c}\text { No/little } \\
\text { treatment need }\end{array}$ & $\begin{array}{c}\text { DHC grade } \\
\text { treatment need }\end{array}$ & $\begin{array}{c}\text { Great/severe } \\
\text { treatment need }\end{array}$ & Total & p-value \\
\cline { 2 - 6 } Class I & $68(26.77 \%)$ & $52(20.47 \%)$ & $134(52.76 \%)$ & 254 & 171 \\
\hline Class II & $6(3.51 \%)$ & $31(18.13 \%)$ & $134(78.36 \%)$ & 39 & $0.000 *$ \\
\hline Class III & $1(2.56 \%)$ & $12(30.78 \%)$ & $26(66.66 \%)$ & $\mathbf{4 6 4}$ \\
\hline Total & $\mathbf{7 5 ( 1 6 . 2 \% )}$ & $\mathbf{9 5 ( 2 0 . 4 \% )}$ & $\mathbf{2 9 4}(\mathbf{6 3 . 4} \%)$ & \\
\hline
\end{tabular}

$p<0.01 *$ Statistically significant

\section{DISCUSSION}

Various malocclusion features have been found to vary with different population, age, gender and ethnicity. The result of our study showed the prevalence of $54.7 \%$ Class I, $36.9 \%$ Class II, $8.4 \%$ Class III malocclusion among referred Nepalese orthodontic patients. These findings serve as reference data for the epidemiology of malocclusion. Table 6 illustrates the malocclusion data of various studies on Nepalese population.

Table 6: Malocclusion data of Nepalese population

\begin{tabular}{|c|c|c|c|}
\hline Study Population & Angle's Class I & Angle's Class II & Angle's Class III \\
\hline $\begin{array}{l}\text { Wada T, Shrestha RM et al' }{ }^{12} \text { (1999) } \\
N=1027 \text { (urban, sub-urban samples of Kathmandu valley) }\end{array}$ & $89 \%$ & $7.6 \%$ & $3.4 \%$ \\
\hline $\begin{array}{l}\text { Bhattarai P \& Shrestha } \mathrm{RM}^{13} \text { (2008) } \\
\mathrm{N}=200 \text { (Referred orthodontic patients of Kathmandu) }\end{array}$ & $54.5 \%$ & $37.5 \%$ & $8 \%$ \\
\hline $\begin{array}{l}\text { Sharma } \mathrm{JN}^{14} \text { (2009) } \\
\mathrm{N}=134 \text { (Dental students of Dharan) }\end{array}$ & $72.38 \%$ & $19.40 \%$ & $5.97 \%$ \\
\hline $\begin{array}{l}\text { Shrestha BK, Yadav R et al' }{ }^{15} \text { (2011) } \\
\mathrm{N}=93 \text { (Medical students of Kathmandu) }\end{array}$ & $44.09 \%$ & $30.1 \%$ & $16.12 \%$ \\
\hline $\begin{array}{l}\text { Shrestha BK, Yadav R et al' }{ }^{16} \text { (2012) } \\
N=937 \text { (School children of Kathmandu valley) }\end{array}$ & $59 \%$ & $25 \%$ & $16 \%$ \\
\hline $\begin{array}{l}\text { Shrestha S \& Shrestha RM (2013) } \\
N=464 \text { (Referred orthodontic patients of Kathmandu) }\end{array}$ & $54.7 \%$ & $36.9 \%$ & $8.4 \%$ \\
\hline
\end{tabular}

The present study found that $63.4 \%$ of the Nepalese orthodontic patients require great or severe treatment need according DHC. However, another study on Nepalese samples from Dharan showed the great or severe treatment need as $11.94 \% .^{14}$ 
The normal occlusal characteristics in Nepalese subjects were $56.2 \%$ normal overjet, $79.3 \%$ normal overbite, $91.8 \%$ without open bite, $76.7 \%$ without cross bite, $34.3 \%$ without displacement and $88.8 \%$ without hypodontia problems.

When the occlusal characteristics of Nepalese subjects were compared with the similar samples of Pakistani population; ${ }^{17}$ severe form of overjet was present in $30.8 \%$ in Pakistanis, $6.9 \%$ in Nepalese. Open bite was present in $2.6 \%$ in Pakistani, $8.2 \%$ in Nepalese, cross bite was present in $22.4 \%$ in Pakistanis and $23.3 \%$ in Nepalese.

The occurrence of increased overjet in Nepalese subjects was $44.2 \%$ and similar study on Nigerian subjects ${ }^{18}$ showed similar results with $43 \%$ overjet. Similar study on female Saudi population seeking orthodontic treatment showed $76 \%$ moderate and $73 \%$ severe overjet in adolescents, and $24 \%$ moderate and $26.3 \%$ severe overjet in adults. ${ }^{19}$

According to the present study; increased overbite was present in $20.7 \%$ whereas Nigerian subjects ${ }^{18}$ had $25.2 \%$. Albarakari et al $^{19}$ showed $78.2 \%$ moderate and $87.5 \%$ severe increased overbite in adolescent Saudi females. Souames et $a^{20}$ showed increased overbite in $15 \%$, increased overbite with gingival contact in $45 \%$ and increased overbite with indentation of labial and palatal gingival in $10 \%$ in French samples.

The anterior or posterior cross bite in Nepalese subjects were $23.3 \%$, however the prevalence rate was reversed in Albarakari et al $^{19}$ with $60.5 \%$ unilateral and $74 \%$ bilateral cross bite in Saudi female subjects. In Iranian 12 years-old children $14.2 \%$ had occurrence of crossbite. ${ }^{21}$ Ajayi et al ${ }^{18}$ showed $21.4 \%$ anterior and $12.2 \%$ posterior cross bite in Nigerian subjects.

In the present study $8 \%$ Nepalese subjects and $8.4 \%$ in Nigerian subjects ${ }^{18}$ had open bite ranging from 1 to 4 $\mathrm{mm}$; contrarily the prevalence of open bite was higher in Saudi females having $46.7 \%$ and $53.3 \%$ in adolescent and adults respectively. ${ }^{19}$ Similarly, $0.7 \%$ Iranian 12 years-old children had openbite. ${ }^{21}$

\section{CONCLUSION}

Nepalese orthodontic patients showed increased overjet in $43.8 \%$ subjects with $6.9 \%$ showing severe form, increased overbite in $20.7 \%$ with $19.2 \%$ subjects showing complete overbite. Varying levels of open bite was found in $8.2 \%$ subjects and cross bite in $23.3 \%$. Displacement was found in $65.7 \%$ with $37.1 \%$ showing displacement more than $4 \mathrm{~mm}$. The study revealed that $2.2 \%$ orthodontic patients require pre-restorative orthodontic treatment for more than one tooth missing.

The study depicted statistically significant association between DHC grades and distribution of malocclusion and gender among Nepalese orthodontic patients. 


\section{REFERENCES}

1. Brunelle JA, Bhat M, Lipton JA. Prevalence and distribution of selected occlusal characteristics in the US population, 1988-1991. Journal of Dental Research1996; 75:706-713.

2. Tschill P, Bacon W,Sonko A. Malocclusion in the deciduous dentition of Caucasian children. European Journal of Orthodontics 1997; 19:361-367.

3. Thilander B, Pena L,Infante C, Parada SS, Mayorga C. Prevalence of malocclusion and orthodontic treatment need in children and adolescents in Bogotà, Colombia. An epidemiologic study related to different stages of dental development. European Journal of Orthodontics 2001; 23:153-167.

4. Angle EH. Treatment of malocclusion of the teeth. Angle's system. Philadelphia: S S White Dental Manufacturing Company; 1907.

5. Baca-Garcia A,Bravo M, Baca P, Baca A,Junco P. Malocclusions and orthodontic treatment needs in a group of Spanish adolescents using the Dental Aesthetic Index. International Dental Journal 2004; 54:138-142.

6. Uğur T, Ciğer S, Aksoy A, Telli A.. An epidemiological survey using the Treatment Priority Index (TPI). European Journal of Orthodontics 1998; 20:189-193.

7. Liepa A, Urtane I, Richmond S, Dunstan F. Orthodontic treatment need in Latvia. European Journal of Orthodontics 2003; 25:279284.

8. Brook PH, Shaw WC. The development of an index of orthodontic treatment priority. European Journal of Orthodontics 1989; 11:309-320.

9. Evans R, Shaw WC. Preliminary evaluation of an illustrated scale for rating dental attractiveness. Eur J Orthod 1987; 9: 314-18.

10. Lunn H, Richmond S, Mitropoutous C. The use of the Index of Orthodontic Treatment Need (IOTN) as a public health tool: A pilot study. Community Dent Health. 1993; 10: 111-121.

11. Burden DJ, Pine CM, Burnside G. Modified IOTN: an orthodontic treatment need index for use in oral health surveys. Community Dent Oral Epidemiol 2001;29: 220-25.

12. Wada T, Mizutani S, Tatsuta U, Shrestha RM. The oral health status of the Kathmandu valley, Nepal: Report of the oral health survey 1997-1999. Osaka University Graduate School of Dentistry. Phect-Nepal. Unpublished Report; 1999.

13. Bhattarai P, Shrestha RM. Prevalence of malocclusion among Nepalese orthodontic patients according to Angle's classification. J Nep Dent Asso 2008; 9:(1)29-35.

14. Sharma JN. Epidemiology of malocclusion and assessment of orthodontic treatment need for the population of eastern Nepal. World J Orthod. 2009; 10(4):311-6.

15. Shrestha BK, Yadav R, Gyawali R, Gupta S. Prevalence of malocclusion among medical students in Institute of medicine, Nepal; a preliminary report. Orthod J Nep $2011 ; 1:(1) 24-7$.

16. Shrestha BK, Yadav R, Basel P. Prevalence of malocclusion among high school students in Kathmandu valley. Orthod J Nep 2012; 2:(1)4-8

17. Erum G, Fida M. Pattern of malocclusion in orthodontic patients: A hospital based study. J Ayub Med Coll Abbottabad 2008; 20(1).

18. Ajayi EO, Ize-lyamu I. Malocclusion and occlusal traits among orthodontic patients seen at the University of Benin Teaching Hospital, Nigeria Nigerian Dental Journal.2010; 18:1.

19. Albarakari S, Sahartaher. Malocclusion traits in Saudi females seeking orthodontic treatment. Pakistan Oral \& Dental Journal $2001 ; 30(1)$.

20. Souames M, Bassigny F, Zenati N, Riordan JP. Orthodontic treatment need in French school children: an epidemiological study using Index of Orthodontic Treatment Need. European Journal of Orthodontics 2006; 28:605-9.

21. Perillo L, Masucci C, Ferro F, Apicella D, Baccetti T. Prevalence of orthodontic treatment need in southern Italian school children. Europen Journal of Orthodontics 2010; 32:49-53. 